\title{
GMR
}

\section{Influence of chitosan nanoparticle-mediated $C$-erbB-2 gene silencing on invasion and apoptosis of Hep-2 cells}

\author{
W.R. Liu ${ }^{1 *}$, L.R. Cao ${ }^{2 *}$ and G.J. Zuo ${ }^{3}$ \\ ${ }^{1}$ Teaching and Research Division of Pathology, \\ Medical College of Yangtze University, Jingzhou, Hubei Province, China \\ ${ }^{2}$ Teaching and Research Division of Surgical Medicine, \\ Hubei College of Chinese Medicine, Jingzhou, China \\ ${ }^{3}$ Department of Ophthalmology, First Hospital of Jingzhou, Jingzhou, \\ Hubei Province, China \\ *These authors contributed equally to this study. \\ Corresponding author: G.J. Zuo \\ E-mail: zuoguojindo@yeah.net
}

Genet. Mol. Res. 15 (4): gmr15048860

Received June 7, 2016

Accepted July 26, 2016

Published October 17, 2016

DOI http://dx.doi.org/10.4238/gmr15048860

Copyright (C) 2016 The Authors. This is an open-access article distributed under the terms of the Creative Commons Attribution ShareAlike (CC BY-SA) 4.0 License.

\begin{abstract}
We aimed to measure the invasion ability of Hep-2 laryngeal cancer cells after treatment with $C$-erbB-2-small interfering RNA (siRNA)-chitosan nanoparticles, and assess the applied value of chitosan nanoparticle-mediated $C$-erbB-2 interference in inhibiting laryngeal cancer invasion and metastasis. Nanoparticles of approximately $100 \mathrm{~nm}$, comprising $C$-erbB-2 siRNA packaged with chitosan, were prepared and used to treat Hep-2 cells. Silencing of C-erbB-2 was detected by western blot and polymerase chain reaction. Cell invasion and apoptosis were estimated by transwell assay and flow cytometry, respectively. C-erbB-2-siRNA-chitosan nanoparticles
\end{abstract}


significantly down-regulated $C$-erbB-2 expression in Hep-2 cells ( $\mathrm{P}$ $<0.05)$, and cell invasion was noticeably decreased. Moreover, they significantly induced apoptosis of the Hep-2 cells $(\mathrm{P}<0.05)$. Chitosan nanoparticle-mediated $C$-erbB-2 gene interference can inhibit the invasion of laryngeal cancer cells and induce their apoptosis.

Key words: Nanoparticles; Chitosan; C-erbB-2; Laryngeal cancer; Apoptosis

\section{INTRODUCTION}

Laryngeal cancer is one of the two most common malignant head and neck tumors, second only to nasopharyngeal carcinoma. Conventional treatment is effective in cases diagnosed early, but not in advanced cases. Infiltration and invasion, the basic biological characteristics of a malignant tumor, lead to poor prognosis of laryngeal cancer and death (Wang et al., 2014). In order to control tumor invasion and metastasis, genes associated with these processes have recently been targeted using RNA interference (RNAi) as gene therapy, to specifically block their expression (Elbashir et al., 2002). With the development of material science, novel nanoparticles with potential value as drug carriers have also attracted wide attention. RNAi gene therapy combined with nanoparticle carriers may be applied in the treatment of tumors.

The $C$-erbB-2 gene, also known as neu, is a $v$-erbB-2-related proto-oncogene (Semba et al., 1985). Studies have demonstrated heightened expression of this gene in a wide variety of tumors, an event closely related to tumor malignancy, metastasis, chemotherapy resistance, and prognosis (Hynes and Stern, 1994). The overexpression and activation of C-erbB-2 not only causes dysregulated cell growth, but also influences the sensitivity of tumor cells to chemotherapeutic drugs, making it a potential target for cancer gene therapy. In order to explore the applied value of nanoparticle-based RNAi gene therapy in limiting laryngeal cancer invasion and metastasis, we targeted the $C$-erbB-2 gene using small interfering RNA (siRNA) technology with a novel chitosan nanoparticle carrier.

\section{MATERIAL AND METHODS}

\section{Main reagents}

Chitosan was purchased from Sigma-Aldrich (St. Louis, MO, USA). C-erbB-2targeting and reference siRNA constructs were designed using online software provided by Ambion (Waltham, MA, USA). The positive-sense strand of the C-erbB-2 siRNA sequence was 5'-AUU GGC UAC UAC CGA AGA G-3', and the negative-sense strand was 5'-CUC UUC GGU AGU AGC CAA U-3'. Lipofectamine 2000 reagent was purchased from Invitrogen (Carlsbad, CA, USA).

\section{Cell culture}

Hep-2 human laryngeal squamous cell carcinoma cells were purchased from the China Center for Type Culture Collection (Wuhan, China) and maintained in our laboratory.

Genetics and Molecular Research 15 (4): gmr15048860 
The cells were cultured in 1640 medium (Gibco, Waltham, MA, USA) containing $10 \%$ fetal bovine serum (FBS; Gibco) at $37^{\circ} \mathrm{C}$ in $5 \% \mathrm{CO}_{2}$.

\section{Preparation of nanoparticles and particle size analysis}

Chitosan was dissolved in $0.3 \mathrm{M}$ sodium acetate solution. The $\mathrm{pH}$ was adjusted to 5.5 with $0.01 \mathrm{M}$ sodium hydroxide, and the final chitosan concentration was $1 \mathrm{mg} / \mathrm{mL}$. Bacteria were filtered and removed by using a $0.22-\mu \mathrm{m}$ syringe filter. Diethylpyrocarbonate (DEPC)treated water was added to siRNA to reach a final concentration of $100 \mu \mathrm{M}$. This siRNA solution $(60 \mu \mathrm{L})$ was mixed with $500 \mu \mathrm{L}$ chitosan in acetic acid/sodium acetate solution $(1 \mathrm{mg} / \mathrm{mL})$ by vortexing for $30 \mathrm{~s}$. The solution was left to stand at $23^{\circ} \mathrm{C}$ for $1 \mathrm{~h}$, yielding $C$-erbB-2-siRNA-chitosan. An appropriate amount of nanoparticle suspension $(0.1 \mathrm{mg} / \mathrm{mL})$ was then diluted with DEPC-treated water. A Malvern (Malvern, UK) granulometer was used to determine the average particle size. DEPC-treated water was used to prepare all of the solutions used in the experiments.

\section{Experimental group and transfection}

Laryngeal cancer Hep-2 cells were divided into five groups. Group 1 was a blank control group cultured under standard conditions. Group 2 had blank chitosan solution added to the culture medium. Group 3 cells were incubated in culture medium containing negative control siRNA-chitosan. Group 4 was treated with $C$-erbB-2-siRNA-liposomes, prepared with Lipofectamine 2000 following the manufacturer protocol. Separately, an appropriate amount $(0.1 \mathrm{mg} / \mathrm{mL})$ of Lipofectamine 2000 and $C$-erbB-2 siRNA were added to serum-free medium, mixed, and left at room temperature for $5 \mathrm{~min}$. Lipofectamine 2000 and $C$-erbB-2 siRNA were then combined by mixing, and incubated at room temperature for $15 \mathrm{~min}$. This solution was subsequently added to complete medium for a final $C$-erbB-2 siRNA concentration of $100 \mathrm{nM}$. Cells in group 5 were treated with $C$-erbB-2-siRNA-chitosan added to the culture medium. The final concentration of $C$-erbB-2 siRNA was $100 \mathrm{nM}$. After supplementation with $10 \%$ FBS, the solution was incubated at $37^{\circ} \mathrm{C}$ in $5 \% \mathrm{CO}_{2}$ for $24 \mathrm{~h}$, after which a transwell assay was performed. Protein and RNA were extracted after $4 \mathrm{~h}$ for western blot and quantitative real-time PCR (qRT-PCR), respectively.

\section{Verification of RNAi efficiency}

The interference efficiency of the $C$-erbB-2-siRNA-nanoparticles was verified by qRT-PCR and western blot. Hep-2 cells were cultured before being treated with TRIzol reagent (Invitrogen), using which, total RNA was extracted. This was then reverse-transcribed into complementary DNA (cDNA) with a RevertAid First Strand cDNA Synthesis kit (Thermo Scientific, Waltham, MA, USA). SYBR Green PCR pre-blended solution (Invitrogen) was used to quantify expression of the $C-e r b B-2$ gene. PCR primers were synthesized by Invitrogen, and were as follows: $C$-erbB-2 sense, 5'-CTT CAA AGG GAC ACC TAC GG-3', and antisense, 5'-CAG CCA TCT GGG AAC TCA A-3'; $\beta$-actin (internal reference) sense, 5'-CTG AGC AGA TCA TGA AGA C-3', and antisense, 5'-CTT GGT GGA CGC ATC CTG AG-3'. qRT-PCR was conducted on an Applied Biosystems (Foster City, CA, USA) 7500 Fast system, and the $2^{-\Delta \Delta C t}$ method was used to analyze the relative expression of mRNA. Total

Genetics and Molecular Research 15 (4): gmr15048860 
protein was extracted from cells in the logarithmic growth phase for western blotting. A NanoDrop 2000 (NanoDrop Products, Wilmington, DE, USA) was used to determine protein concentration. Protein samples were mixed with five times their volume of loading buffer and incubated in a dry bath at $95^{\circ} \mathrm{C}$ for $10 \mathrm{~min}$ for denaturation. Each sample (30 $\mu \mathrm{g}$ ) was subjected to sodium dodecyl sulfate polyacrylamide gel electrophoresis (SDSPAGE) on a 10\% gel. "Precast" gel was purchased from Thermo Fisher Scientific (USA). The proteins of interest were transferred to a polyvinylidene fluoride membrane using a semi-dry transfer instrument. The membrane was then blocked with Tris-buffered salineTween 20 containing 5\% skim milk powder, incubated at $4^{\circ} \mathrm{C}$ overnight with a $C$-erbB-2 primary antibody, and exposed to a secondary antibody at room temperature for $90 \mathrm{~min}$. It was subsequently treated with enhanced chemiluminescence reagents in a dark room and detected by using an X-ray film, which was then developed and fixed. Anti-C-erbB-2 and $\beta$-actin rabbit primary antibodies and secondary antibody were purchased from Santa Cruz Biotechnology (Dallas, TX, USA).

\section{Invasion assay}

The transwell method was used to measure laryngeal cancer cell invasion ability. Transwell inserts pre-packed with a matrix (pore size: $8 \mu \mathrm{m}$ ) were purchased from Invitrogen. The experiment was carried out following the manufacturer protocol. Transwell inserts were placed on 24-well plates, the wells of which held $0.7 \mathrm{~mL}$ RPMI 1640 culture medium containing 10\% FBS. Cells suspended in serum-free medium $(0.2 \mathrm{~mL})$ were then injected into the upper chamber of the inserts. The number of cells in each well was $2 \times 10^{4}$, and three control wells were included for each experimental group. All cells were cultured for $24 \mathrm{~h}$, fixed with methanol, and stained by using crystal violet. Five visual fields were randomly selected under a microscope at $20 \mathrm{X}$ magnification, and the number of cells penetrating the chambers was counted, as a measure of invasion ability. Averages and standard deviations were calculated.

\section{Detection of cell apoptosis by flow cytometry}

Digested cells were harvested and washed twice with $1 \mathrm{X}$ phosphate-buffered saline, before being centrifuged at $1000 \mathrm{rpm}$ at room temperature for 3 min. The supernatant was then discarded and the cells were resuspended in binding buffer. Following incubation with $10 \mu \mathrm{L}$ fluorescein isothiocyanate-conjugated annexin $\mathrm{V}$ and $5 \mu \mathrm{L}$ propidium iodide at room temperature in the dark for $15 \mathrm{~min}$, flow cytometry was used to detect the percentage of apoptotic cells.

\section{Statistical analysis}

All data were analyzed by using SPSS 22.0 (IBM Corp., Armonk, NY, USA), and are reported as means \pm standard deviations. $\mathrm{P}<0.05$ was considered to represent a statistically significant difference. The independent-samples $t$-test was used for pairwise comparison of means. All experiments were repeated three times.

Genetics and Molecular Research 15 (4): gmr15048860 


\section{RESULTS}

\section{Particle size analysis}

Chitosan nanoparticles containing $C$-erbB-2 siRNA were prepared in order to determine their effects on $C$-erbB-2 gene expression and laryngeal cancer cell invasion. The average size of these siRNA-chitosan nanoparticles was $100 \mathrm{~nm}$ (Figure 1), which met the requirements of the current application.

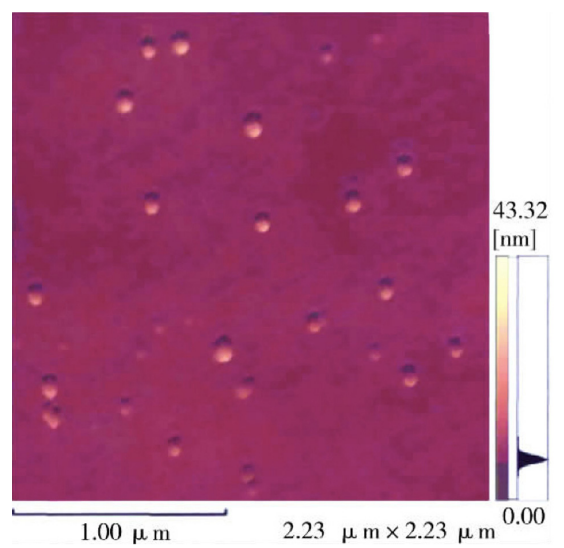

Figure 1. Atomic force microscopy image of small interfering RNA-chitosan nanoparticles (40,000X magnification).

\section{Interference efficiency}

qRT-PCR and western blot showed that the $C$-erbB-2-siRNA-chitosan nanoparticles effectively interfered with $C$-erbB-2 expression in Hep-2 cells (Figures 2 and 3). Relative expression of $C$-erbB-2 mRNA was significantly lower in the $C$-erbB-2-siRNA-chitosan group $(0.47 \pm 0.06)$ than that in the blank control $(1.14 \pm 0.13)$, blank chitosan $(0.94 \pm 0.07)$, and negative control groups $(0.89 \pm 0.12 ; \mathrm{P}<0.01)$, but was similar to that in the $C$-erbB-2siRNA-liposome group $(0.51 \pm 0.14 ; \mathrm{P}=0.142)$. $C$-erbB-2 protein expression of cells in the different groups was also detected.

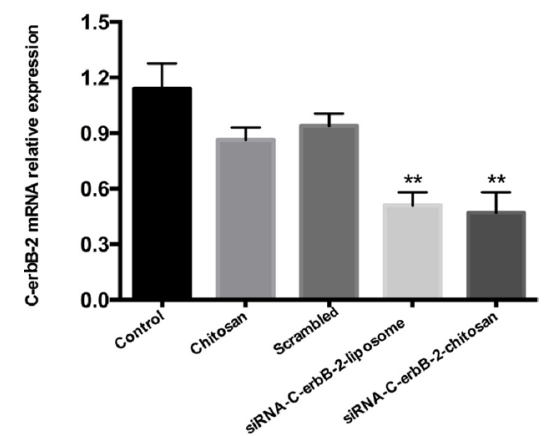

Figure 2. Real-time polymerase chain reaction showed that $C$-erbB-2-small interfering RNA (siRNA)-chitosan nanoparticles significantly reduced $C$-erbB-2 mRNA expression $(* * \mathrm{P}<0.01)$. 


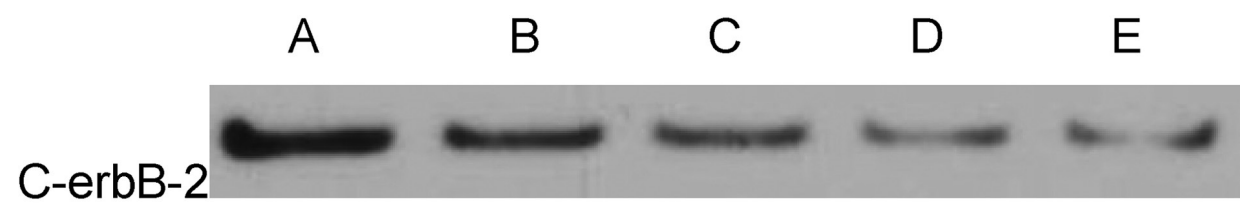

\section{$\beta$-actin}

Figure 3. Western blotting showed that $C$-erbB-2-small interfering RNA (siRNA)-chitosan nanoparticles significantly reduced $C$-erb $B-2$ protein expression (lane $A=$ control; lane $B=$ chitosan; lane $C=$ scrambled; lane $D=C$-erbB-2-siRNA-liposome; lane $E=C$-erbB-2-siRNA-chitosan).

\section{Invasion of $C$-erbB-2-siRNA-nanoparticle-treated laryngeal cancer cells}

In Hep-2 cells, $C$-erbB-2-siRNA-chitosan nanoparticles effectively interfered with expression of the $C-e r b B-2$ gene, which correlates highly with the invasion and metastasis of laryngeal cancer. To determine the influence of these nanoparticles further, a transwell assay was used to measure the invasion ability of cells in each group. Invasion of Hep-2 cells treated with $C$-erbB-2-siRNA-nanoparticles (58.4 \pm 1.42 cells/visual field) was significantly reduced compared to that of blank control (139.17 \pm 4.02 cells/visual field), blank chitosan (132.62 \pm 2.54 cells/visual field), and siRNA-chitosan cells $(127.16 \pm 4.54$ cells/visual field; $\mathrm{P}<0.01$; Figures 4 and 5), but was similar to that of the $C$-erbB-2-siRNA-liposome group ( $62.43 \pm 4.43$ cells/visual field; $\mathrm{P}=0.203$ ). Therefore, $C$-erbB-2-siRNA-chitosan nanoparticles inhibited the invasion of laryngeal cancer cells.

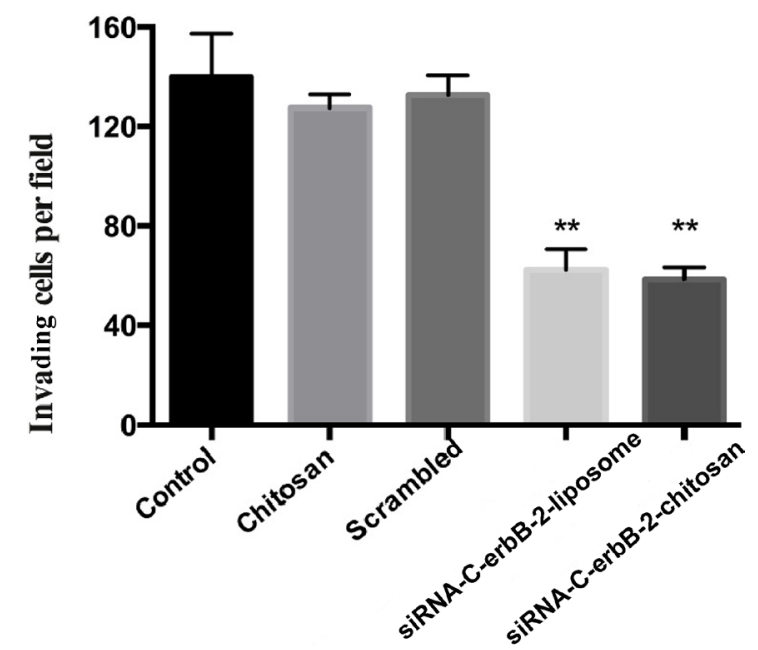

Figure 4. Transwell assays showed that $C$-erbB-2-small interfering RNA (siRNA)-chitosan nanoparticles significantly reduced invasion of Hep-2 cells $(* * \mathrm{P}<0.01)$.

Genetics and Molecular Research 15 (4): gmr15048860 

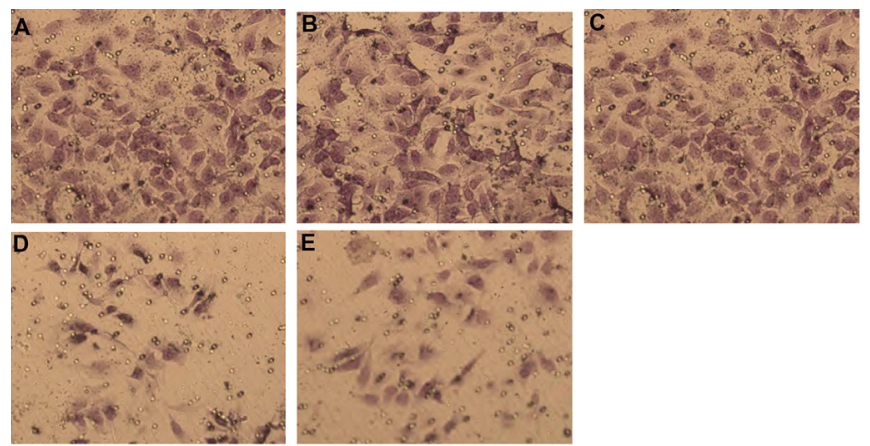

Figure 5. Transwell assays showed that $C$-erbB-2-small interfering RNA (siRNA)-chitosan nanoparticles effectively reduced invasion of Hep-2 cells (A. control; B. chitosan; C. scrambled; D. C-erbB-2-siRNA-liposome; E. $C$-erbB-2-siRNA-chitosan).

\section{Influence of $C$-erbB-2-siRNA-nanoparticles on apoptosis of laryngeal cancer cells}

Flow cytometry showed that the rate of apoptosis among Hep-2 cells treated with $C$-erbB-2-siRNA-nanoparticles was $26.23 \pm 1.23 \%$, which was significantly different from that in the blank control $(4.23 \pm 0.67 \%)$, blank chitosan $(5.41 \pm 0.46 \%)$, and siRNA-chitosan groups $(5.77 \pm 0.31 \% ; \mathrm{P}<0.01)$. However, this rate was similar to that of $C$-erbB-2-siRNAliposome cells $(27.11 \pm 2.23 \% ; \mathrm{P}=0.215)$. Thus, $C$-erbB-2-siRNA-chitosan nanoparticles induced apoptosis of laryngeal cancer cells (Figure 6).

A

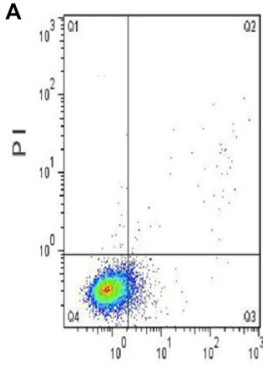

Annexin V-FLOUS

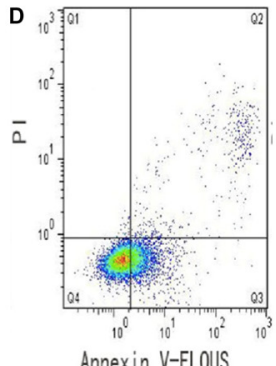

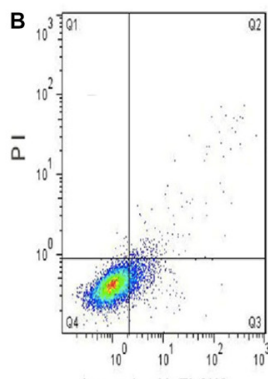

Annexin V-FLOUS

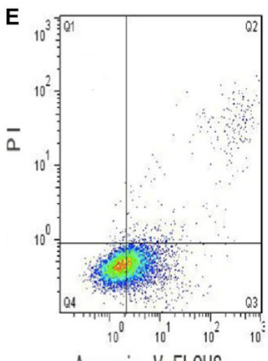

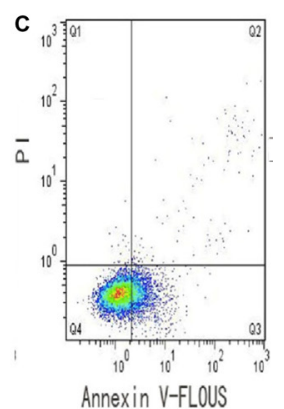

Annexin V-FLOUS

Figure 6. Flow cytometry showed that $C$-erbB-2-small interfering RNA (siRNA)-chitosan nanoparticles induced Hep-2 cell apoptosis (A. control; B. chitosan; C. scrambled; D. C-erbB-2-siRNA-liposome; E. C-erbB-2-siRNAchitosan). $\mathrm{PI}=$ propidium iodide.

Genetics and Molecular Research 15 (4): gmr15048860 


\section{DISCUSSION}

The incidence of laryngeal cancer in China has been increasing in recent years; however, the underlying mechanism responsible for this remains unclear. The $C-e r b B-2$ gene is a cell-derived oncogenic factor. It is a homolog of the gene neu, also known as HER-2, and a member of the epithelial growth factor receptor family, located in the $17 \mathrm{q} 21$ region. It encodes a $185-\mathrm{kDa}$ transmembrane glycoprotein associated with tyrosine kinase activity. Under normal circumstances, the $C$-erbB-2 gene is inactive, participating in the regulation of cell growth and differentiation. When affected by internal and external factors, its genetic structure or expression is disturbed, potentially promoting tumorigenesis. Overexpression of $C$-erbB-2 closely correlates with the occurrence of a variety of malignant tumors, including those of the breast, lung, and stomach (Mahlknecht et al., 2013; Silva et al., 2013). In addition, $C$-erbB-2 is associated with tumor growth, metastasis, and drug resistance (Tzahar and Yarden, 1998; Nicholson et al., 2001), making it a potential target for cancer gene therapy.

To date, several biological carriers have been used to target genes. Chitosan nanoparticles, which are non-toxic, stable, injectable, and biodegradable, without inducing an immune response, have been recently highlighted (Choi et al., 2004; Lee et al., 2005; Jiang et al., 2008). Although the efficiency of liposome-mediated transfection is high and the technology is established, its application is limited because of a tendency for degradation. Chitosan nanoparticles are a novel material that have been applied in the treatment of diseases, drug delivery, and ultrasonic imaging, with satisfactory outcomes (Chen et al., 2012; Shilpa and Paulose, 2014; Yang et al., 2016). The chitosan nanoparticles prepared in this study were spherical with a uniform appearance and good dispersion characteristics. Nano-crystallization of chitosan can increase its solubility in aqueous solutions, especially at physiological $\mathrm{pH}$, and improve its absorption by the respiratory mucosa epithelium (Mooren et al., 1998; Janes et al., 2001). Delivery by chitosan nanoparticles can protect siRNA from degradation, prolong the duration of its circulation in blood, and improve transfection efficiency. For tumor treatment, chitosan nanoparticles can be used alone for the delivery of drugs to enhance therapeutic effects. Moreover, they can be modified chemically to allow targeted therapy, furthering augmenting treatment specificity (Zhao et al., 2007; Zheng, 2013). Chitosan itself can also directly inhibit tumor cells and promote the anticarcinogenic effects of drugs in humans through activation of the immune system, thus playing a synergic role with other anticancer drugs (Kandra and Kalangi, 2015).

In this study, when Hep-2 cells were transfected with C-erbB-2 siRNA using chitosan nanoparticles as carriers, C-erbB-2 gene and protein expression and cell migration and invasion were significantly inhibited, with apoptosis being induced. Accordingly, $C$-erbB-2 was associated with the invasion and growth of laryngeal cancer cells, and chitosan nanoparticle-mediated interference with this gene shows potential value in gene therapy applications for laryngeal cancer. It seems likely that siRNA silencing of the $C$-erbB-2 gene affected the regulation of related molecules in the PI3K/AKT signaling pathway. This pathway is involved in many cellular processes, participating in growth, proliferation, differentiation, and regulation (Luo et al., 2006). C-erbB-2 expression may result in a reduction in PI3K, AKT, and phosphorylated AKT levels, accompanied by an increase in p27.

Notably, many of the experiments in this study were conducted outside organisms and cells. One of the chief weaknesses of in vitro investigations is that they fail to replicate the precise cellular conditions present within an organism. Therefore, in vivo studies should be performed in the future.

Genetics and Molecular Research 15 (4): gmr15048860 


\section{Conflicts of interest}

The authors declare no conflict of interest.

\section{REFERENCES}

Chen M, Gao S, Dong M, Song J, et al. (2012). Chitosan/siRNA nanoparticles encapsulated in PLGA nanofibers for siRNA delivery. ACS Nano 6: 4835-4844. http://dx.doi.org/10.1021/nn300106t

Choi WJ, Kim JK, Choi SH, Park JS, et al. (2004). Low toxicity of cationic lipid-based emulsion for gene transfer. Biomaterials 25: 5893-5903. http://dx.doi.org/10.1016/j.biomaterials.2004.01.031

Elbashir SM, Harborth J, Weber K and Tuschl T (2002). Analysis of gene function in somatic mammalian cells using small interfering RNAs. Methods 26: 199-213. http://dx.doi.org/10.1016/S1046-2023(02)00023-3

Hynes NE and Stern DF (1994). The biology of erbB-2/neu/HER-2 and its role in cancer. Biochim. Biophys. Acta 1198: $165-184$.

Janes KA, Fresneau MP, Marazuela A, Fabra A, et al. (2001). Chitosan nanoparticles as delivery systems for doxorubicin. J. Control. Release 73: 255-267. http://dx.doi.org/10.1016/S0168-3659(01)00294-2

Jiang HL, Kim TH, Kim YK, Park IY, et al. (2008). Efficient gene delivery using chitosan-polyethylenimine hybrid systems. Biomed. Mater. 3: 025013. http://dx.doi.org/10.1088/1748-6041/3/2/025013

Kandra P and Kalangi HP (2015). Current understanding of synergistic interplay of chitosan nanoparticles and anticancer drugs: merits and challenges. Appl. Microbiol. Biotechnol. 99: 2055-2064.http://dx.doi.org/10.1007/s00253-015-6384-9

Lee MK, Chun SK, Choi WJ, Kim JK, et al. (2005). The use of chitosan as a condensing agent to enhance emulsionmediated gene transfer. Biomaterials 26: 2147-2156. http://dx.doi.org/10.1016/j.biomaterials.2004.07.008

Luo J, Sobkiw CL, Hirshman MF, Logsdon MN, et al. (2006). Loss of class IA PI3K signaling in muscle leads to impaired muscle growth, insulin response, and hyperlipidemia. Cell Metab. 3: 355-366. http://dx.doi.org/10.1016/j. cmet.2006.04.003

Mahlknecht G, Maron R, Mancini M, Schechter B, et al. (2013). Aptamer to ErbB-2/HER2 enhances degradation of the target and inhibits tumorigenic growth. Proc. Natl. Acad. Sci. USA 110: 8170-8175.http://dx.doi.org/10.1073/ pnas. 1302594110

Mooren FC, Berthold A, Domschke W and Kreuter J (1998). Influence of chitosan microspheres on the transport of prednisolone sodium phosphate across HT-29 cell monolayers. Pharm. Res. 15: 58-65. http://dx.doi. org/10.1023/A:1011996619500

Nicholson RI, Gee JM and Harper ME (2001). EGFR and cancer prognosis. Eur. J. Cancer 37 (Suppl 4): S9-S15. http:// dx.doi.org/10.1016/S0959-8049(01)00231-3

Semba K, Kamata N, Toyoshima K and Yamamoto T (1985). A v-erbB-related protooncogene, c-erbB-2, is distinct from the c-erbB-1/epidermal growth factor-receptor gene and is amplified in a human salivary gland adenocarcinoma. Proc. Natl. Acad. Sci. USA 82: 6497-6501.http://dx.doi.org/10.1073/pnas.82.19.6497

Shilpa J and Paulose CS (2014). GABA and 5-HT chitosan nanoparticles decrease striatal neuronal degeneration and motor deficits during liver injury. J. Mater. Sci. Mater. Med. 25: 1721-1735.http://dx.doi.org/10.1007/s10856-014-5195-3

Silva JG, Sánchez V, Polo SM and González CA (2013). Expression of c-erbB-2 in breast cancer cell lines as experimental receptor of magnetic nanoparticles. Conf. Proc. IEEE Eng. Med. Biol. Soc. 2013: 4498-4501.

Tzahar E and Yarden Y (1998). The ErbB-2/HER2 oncogenic receptor of adenocarcinomas: from orphanhood to multiple stromal ligands. Biochim. Biophys. Acta 1377: M25-M37.

Wang Q, Chen H and Zhou S (2014). Typical laryngeal carcinoid tumor with recurrence and lymph node metastasis: a case report and review of the literature. Int. J. Clin. Exp. Pathol. 7: 9028-9031.

Yang AQ, Wang PJ, Huang T, Zhou WL, et al. (2016). Effects of monomethoxypolyethylene glycol-chitosan nanoparticlemediated dual silencing of livin and survivin genes in prostate cancer PC-3M cells. Genet. Mol. Res. 15: http://dx.doi. org $/ 10.4238 /$ gmr. 15027430.

Zhao WM, Xu Y, Wang YM, Cheng ZK, et al. (2007). HSV-tk gene delivered by chitosan nanoparticles killed prostate cancer cells in vitro. Tumor 27: 210-213.

Zheng L (2013). In vitro response of breast cancer cells (MCF-7) to albumin coated chitosan nanoparticles. China J. Modern Med. 23: 33-36.

Genetics and Molecular Research 15 (4): gmr15048860 